\title{
4. PROPOSALS REGARDING WORK STRATEGIES IN VISUAL ARTS ACTIVITIES II. CREATING AN INTERROGATIVE ATTITUDE
}

\author{
Ana-Maria Aprotosoaie-Iftimi ${ }^{199}$
}

\begin{abstract}
Between the age of six and eleven, children easily express themselves through drawing. After this age, there is a blockage due to the development of critical thinking. If during the 6 - 11 age stage children draw using symbol schemes, reporting what they remember and what they understood from what they saw, after the age of 10-11 (secondary phase) children want to draw what they see and thus they face challenges related to technical means and language specific for arts. In this regard, a mediation is necessary between the technical means and the artwork or reproductions of fine art (either in albums, or displayed on a screen) using guided questions. This process, that over the years of teaching proved its efficiency, contributes to the development of students' imagination and creativity, and to the formation of a useful general culture.
\end{abstract}

Key words: guided questions, art language, creativity, frameworks for interpreting artworks

\section{Introducation}

The greatest challenge for a teacher, during the visual arts education classes, is finding a way to encourage students to give time, attention and understanding to artworks. The multitude of images children see on television, in magazines or on the street (through billboards) develops an undifferentiated perception, which can lead to the inability to analyze images and to reflect on their meaning. Thus, when they visit an art gallery or an art museum, they will not be able to identify the meanings they themselves attribute to the works, or they will not be able to make a deeper analysis and they will move quickly from one image to another. From this perspective, the practice of using art reproductions during plastic education classes as a starting point for analyzing and interpreting artists' works is an effective method. Observing artists' works, children can learn about the manner in which things, phenomena, feelings can be perceived, imagined or interpreted and transposed into visual-plastic images. For example, outside the workshop, in the surrounding environment, many phenomena we want children to observe are complex and transient (such as light or clouds and running water), which require descriptions and appropriate explanations.

Below, we propose some concrete examples of activities in three strategies for interacting with artists' creations. The examples can easily be approached during the didactic activity at visual-plastic education classes, regardless of the student's level of study (secondary education or high-school), and regardless of the profile of the school they attend (theoretical or vocational).

\footnotetext{
${ }^{199}$ Lecturer PhD., "George Enescu” National University of Arts from Iaşi, Romania, email: anamariaiftimi@gmail.com
} 


\section{Studying works of art}

By studying works of art, the learner/student acquires knowledge and forms his/her intellectual and practical skills by viewing, researching and studying works of art belonging to various historical (artistic) periods together with the teacher.

Before using an artwork as a starting point for the acquisition of plastic language elements, procedures, working techniques, it is necessary to analyze that work. Thus, pupils can engage both personally (in an ascertaining manner) and appreciativelly (in a critical manner) in the interpretation of art works, thus forming the basis of visual-artistic education. Students can be well trained in the field of visual language, and they can learn the techniques and procedures of drawing, painting, but at the same time they have to learn how to ask questions about artworks. Without questions there are no answers and without answers there is the possibility that art becomes silent, meaningless, irrelevant to children. Throughout the years of experience with the public, students and teachers, the team of artists and art critics at the Tate Modern ${ }^{200}$ in the UK identified ways to approach, present, decipher and discover the artwork in the gallery. Thus, four distinct frames of interpretation of artworks are proposed: the personal approach, ways of approaching the subject of the work, ways of approaching the work as an object itself, ways of approaching the context in which the work was created and exposed. For each frame, there are several levels of analysis, and for each level, the team proposed key questions to guide the interpretation and to facilitate the discovery of the meanings of the works from the gallery/museum/space of exposure:

In this analytical context, the personal approach refers to the personal and social experience of each individual. The ideas and convictions of each of us determine the questions and answers related to artworks, and this should not be ignored, but it should be the starting point for interpreting an art work. Here we can ask questions about: the first reaction to the art work; arguments about the emotional reactions triggered by the work, the way in which the environment, values, experience, beliefs influence these experiences. The degree of interaction between the level of analysis the Personal Approach, the Subject, the Object, and the Context is illustrated and represented in the picture below.

The object refers to the physical presence of the work, to the work of art as an object itself. Every artwork has its qualities, regardless of the style and period to which it belongs. In this way, it is possible to analyze the materials, the work process, to talk about line, tone, color, space etc. Here you can ask questions about: color/shape/surface/work manner, the reason and the way the artist used certain colors, shapes, a certain working manner; the type of materials used and their importance; the process of creation, the work stages; the dimensions of the work; space/position/environment, if the illusion of space is created or is it real space, how is the viewer determined to position himself

\footnotetext{
${ }^{200}$ Charman Helen, Rose Katherine, Wilson Gillian, The Art Gallery Handbook. A Resource for Teachers, Tate Publishing, London, UK, 2006, pag. 57.
} 
towards the work; the working time involved, is there a real time or a fictional time involved. The degree of interaction between the level of examination Object and Personal Approach, the Subject, the Context is illustrated in the picture below.

The subject refers to the content of the work, to the message sent. Each thing says something, through the title, through its content, through the type of work. Questions can be asked about: thematic content; the message transmitted by the work, symbols; the title and the way it is perceived; the genre or type of work. The degree of interaction between the level of analysis The Subject and Personal Approach, Object, Context is illustrated in the picture below.

The Context refers to the relationship with the whole world, with the surrounding world. An artwork can not exist on its own. Examining information such as who made it, when, how was it done, can generate new meanings. Similarly, the present as well as the past can change the light in which a work is perceived. For example, moments and aspects such as politics of the time, society, science, visual culture can influence the way we look at an artwork.

Questions can be asked about: the moment, place and time the work was created; the historical and political time when the work was done; how the work is percieved today, and how it differs from the way it was perceived when it was made; how it relates with other arts or other fields, for example music, theater, science, psychology; the place where the work is currently located and how the work relates to the other works around it. The degree of interaction between the level of analysis Context and Personal Approach, Subject, Object is illustrated in the picture below.

By asking questions about the artworks and by interpreting them, reflecting on them, the life experience improves. Students, who consider themselves less proficient in working techniques, or who are less skillful, have the opportunity to grow by generating personal views about artworks. At the same time, it is possible to link art theory knowledge, art history knowledge and artistic practice. Self-esteem can grow, students gaining confidence in their own opinions, developing the motivation to share ideas and the ability to use a specific vocabulary in a concrete context, creative thinking develops through the birth of new ideas, communication skills improve, problem solving skills develop by making connections, comparisons between information. The abovementioned model can be easily adapted to the usual design of a visual education class.

\section{Direct contact with artistic works}

Through direct contact with artists' works (exhibitions, galleries, films, albums), the learner's competences are developed in direct interaction with the objects and forms of artistic expression, through direct interaction with artists or through direct interaction with artworks in the exhibition spaces. After the students came into contact with the work of art and they assimilated the context in which it was realized, the interaction can continue in the form of analysis, interpretation, reinterpretation, decomposition and recomposition of the works. 
Below are presented some other ways in which the teacher can encourage students to develop an exploratory attitude towards the artwork they took direct contact with:

- Before generating a classroom discussion, it is more productive for students to talk to each other or in groups. Thus, students can be divided into five or six groups. Each group is given the same set of reproductions, and each group is required to decide a hierarchy of the works, depending on how much they feel attracted to the images. Each group must present the choices they made and justify them. The teacher asks questions about the choices made, directing the discussion so that the pupils make a clear distinction between the content and the visual elements used by the artist.

- The spontaneous choice of artworks according to the given theme can generate interesting discussions, but the teacher can deliberately choose certain works that can exemplify and support certain topics of discussion, such as: works done in a reduced chromatic range, paintings with dramatic lights and dark-light contrast, paintings in which the same subject was treated differently.

- Because images are part of our everyday life, students need to be encouraged to differentiate and observe details. Beyond a glance, the meaning of a work can be discovered if students are asked to find, for example, three aspects/parts of the work that are more interesting or three parts of the work that are different from each other.

- An artist's creation can be used as a material for the pupil's personal development. Through their content, paintings can be inventive at the level of the narrative they transmit. For example, it is possible to analyze a work containing characters and students can ask themselves how was that artwork painted, what happened before it was painted and after it was painted, how are the real characters when they do not pose for the artist, how would they present their family in a similar or familiar situation, etc.

- Imagining the work as a frame in a movie can lead to interesting interpretations of what happened five minutes before and five minutes after the frame was played.

- In discussions with students, one can take into account the fact that a work can be presented to the public in different contexts: famous paintings can be used to decorate familiar objects, for example reproductions can appear on stamps, clothes, chocolate packs, tea boxes or to advertise some products. From this, the question may arise whether the same work is perceived differently, or the same when it is in a gallery or is played in a calendar or on a bilboard.

- A very useful way to help children understand how a work is done is to reconstruct it from aproximately the same materials as the objects used in the painting. There can be discussions about it and comparisons between the real image and the painted one, underlining whether the artist was selective or not, when he/she painted the real image. These discussions can be the starting point for children's work on similar topics. 


\section{Direct engagement in artistic practice}

Through direct engagement in artistic practice, the student develops skills and abilities through his/her own artistic experience. In many artistic activities, the student's own work may start from a work that he/she analyzed. But it must be taken into consideration that copying an artist's work can be valuable if, through this process, the students' skills and ability to understand are developed. Copying an artwork has no educational value because it only facilitates an easy way to produce a beautiful piece of work. Working on art reproductions has a concrete and positive outcome when children's attention is channeled to particular aspects that they can learn. Making a copy is a way of exploring the techniques and methods used by the artist, but it is just the first step in helping children to create their own work system. We present some suggestions through which a work of art can be practically interpreted by students:

- A painting can be divided into sections, and each student has to interpret a particular section in such a way as to fit with the one of the colleague (resulting in a group puzzle).

- A painting is projected onto a carved wall. Each student chooses a favourite part and works by using another technique, another style, other materials, etc.

- Students are presented with a small scale reproduction, and the work has to be done on a large scale, natural scale or oversized scale, and vice versa.

- Students are required to interpret a painting in a different color range, which can generate discussion about how color can change the way a work is perceived.

- Paintings with the same theme content, but belonging to different styles/schools can be compared. Students may be required to interpret a painting in the style of another artist.

- Students can be divided into groups and each group is given a painting. Each student must observe and analyze the work in a personal manner and make a detailed, written comment. They can be given some clues that they must not omit in the description: content, meaning, atmosphere, plastic language elements, working manner. Descriptions are exchanged among groups and each student will make an artwork based on the received description. In the end, the descriptions, the students' works and the interpreted artwork will be compared. One can work with parallel groups, of the same level and students can exchange the descriptions of the same work among various classes.

\section{Conclusions}

An art work is the embodiment of the artist's world, which he/she has shared through specific materials, means and techniques. For students to have a meaningful encounter with a work of art, they need to know how to interpret it in order to be able to perceive the artist's world. This involves expanding learning beyond the formal language of visual art (line, form, color) and training one's technical skills. Working skills must be formed in parallel with the development of a specialized vocabulary and the ability to analyze, interpret, 
explore and express ideas. Visual art develops visual-plastic creativity, as well as general creativity, it develops cognitive intelligence, but also emotional and social intelligence. Art determines creative behaviors such as: to ask and to provoke; to make connections and to establish/see relationships; to sense what might be; to explore ideas leaving open options; the interrogative-critical attitude towards actions, ideas and results.

\section{Bibliography}

1. Addison, Nicholas, Burgess Lesley, (2007), Learning to Teach Art and Design in the Secondary School. A Companion to School Experience. Second Edition, London and New York. Routledge Taylor \& Francis Group., London.

2. A.V.I., S.A.P., (2007), Periferic 7. Focussing Iași/Social Processes. International Biennial for Contemporary Art, Asociația Vector Iași \& Siemens Arts Program, Editura Polirom și Revolver, Iași.

3. Charman, Helen; Rose, Katherine; Wilson, Gillian, (2006), The Art Gallery Handbook. A Resource for Teachers, Tate Publishing, London, UK.

4. Clement, Robert, Thomas, (1993), The Art teacher's Handbook. Second Edition, Stanley Thornes (Publishers) Ltd., London, U.K..

5. C.I.S.R., D.T.E., (2016), Review of Artistic Education. No. 11-12/2016, Center of Intercultural Studies and Research, Department for Teachers Education, "George Enescu" University of Arts, Iași, Artes Publishing House, Iași.

6. Dowing, Dick; Watson, Ruth, (2004), School art: What's in it? Exploring Visual Arts in Secondary Schools, National Foundation of Educational Research, London, UK.

7. Hegyi, Dora; László, Zsuzsa, (coord.), (2008), Periferic 8 - Art as Gift. Biennial for Contemporary Art, Editura Grup Mușatinii, Suceava.

8. Hickman, Richard, (2000), Art Education 11-18. 2nd Edition, Continuum, London and New York.

9. Holm, Anna, Marie, (2005), The Art Club- a journey with experiment and enthusiasm, Herning: Av form, Denmark.

10. Isaksen, Scott G., et.al., (1994), The assessment of creativity: An occasional paper from the creativity based information resources project, New York: Center for Studies in Creativity, Buffalo, S.U.A..

11. Lindauer, Martin S., (1998), Interdisciplinarity, the Psychology of Art and Creativity: an Introduction, în Creativity Research Journal, vol.11, nr.1, 1998, p.10.

12. Rayment, Trevor, 2007), The Problem of Assesment in Art and Design, Intellect Books, Bristol, U.K..

13. Weintraub, Linda, (2003), Making contemporary art. How today`s artists think and work, London. Tames \&Hudson.

14. Wilson, Simon, Lack, Jessica, (2008), The Tate Guide to Modern Art Terms, London: Tate Publishing Ltd.

15. Wright, Peter, (2009), Teaching in Arts Education, in Saha Lawrence J. \& Dworkin Gary (Ed.), International Handbook of Research on Teachers and Teaching, Editura Springer International Handbooks of Education, Volume 21, 2009, p. 1029 1040 . 